DIVERSO E PROSA
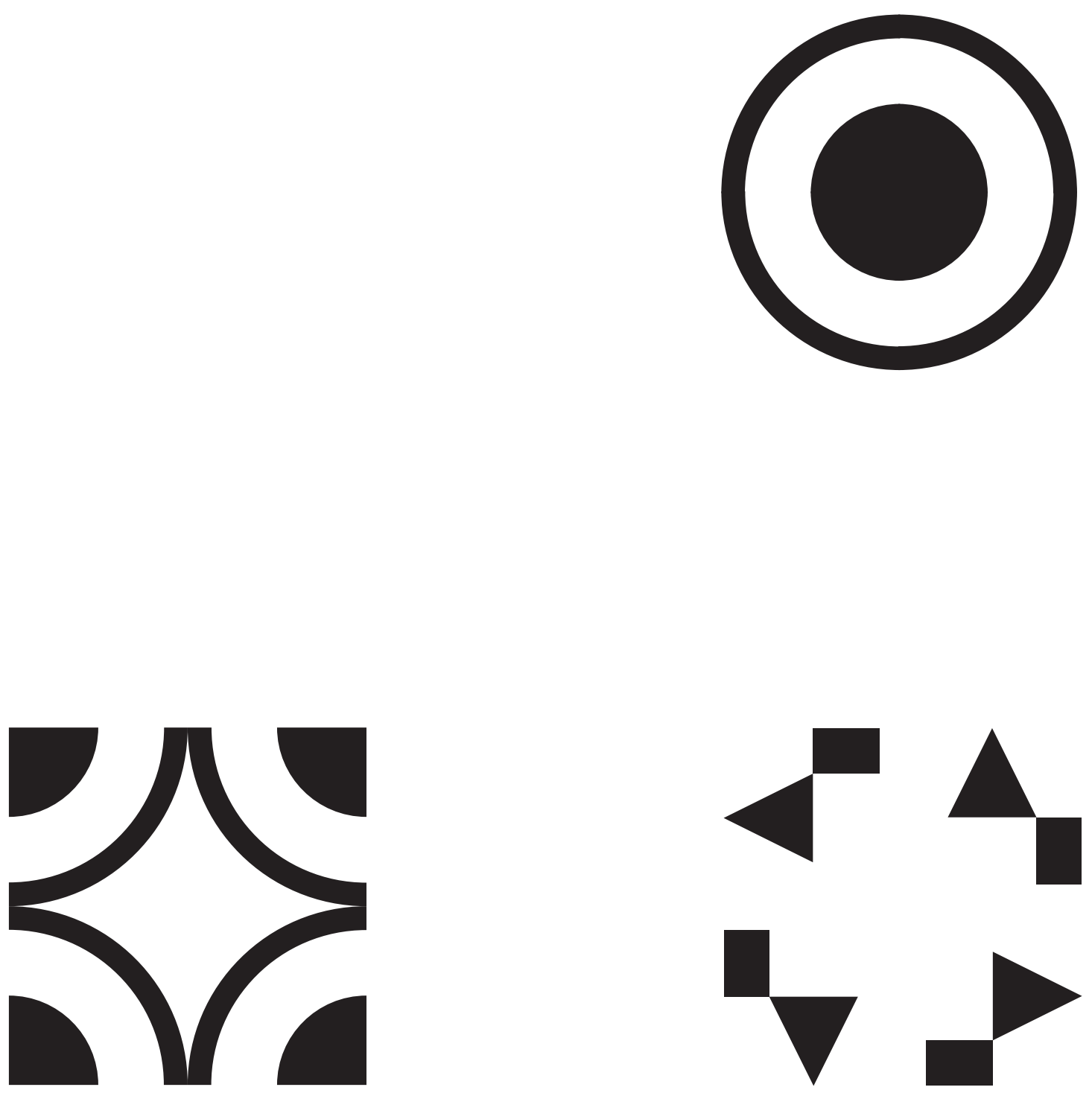
240 


\title{
Apresentação de "Observações preliminares sobre a percepção social do corpo"
}

\author{
Carolina Pulici *
}

Publicado originalmente em 1977, na revista Actes de la recherche en sciences sociales, o artigo de Pierre Bourdieu ora traduzido no Brasil lança várias proposições "preliminares" que se tornarão, entretanto, essenciais e bastante recorrentes no contexto de sua obra. A diferença entre o "corpo real" e o "corpo legítimo", a desigual distribuição das propriedades corporais valorizadas, o “corpo percebido" e a distinção em função do nível de aproximação da cultura e de distância da natureza, são algumas das questões brevemente discutidas neste pequeno texto, porém retomadas e desenvolvidas mais sistemática e exaustivamente em vários de seus livros subsequentes, como $L a$ distinction (1979), La domination masculine (1998) e Le bal des célibataires (2002).

Seus comentários acerca de todo o investimento em tempo, dinheiro e energia destinado a transformar o corpo e a aproximá-lo da conformação tida por legítima parecerão muito atuais ao leitor brasileiro, acostumado a um país que ocupa o segundo lugar (atrás dos Estados Unidos) no ranking mundial de cirurgias plásticas (Yarak; Rosa, 2012). Tais análises sobre as intervenções nos aspectos modificáveis do corpo complementam as reflexões sobre as maneiras de se portar, se comportar, "dar o corpo em espetáculo", como ele diz em Le bal des célibataires, já que o corpo seria, dentre todas as propriedades da "pessoa", a que expressaria mais adequadamente seu "ser profundo" e sua "natureza". Assim, neste livro que descreve como o processo de integração estatal, que por sua vez generalizou o ideal de estilo de vida parisiense, lançou ao descrédito os usos corporais conciliados com a civilização rural e as maneiras viris outrora valorizadas
* Universidade Federal de São Paulo (Unifesp), Guarulhos, São Paulo, Brasil. carolinapulici@gmail.com 
(e exigidas) dos camponeses, Bourdieu afirma que é na tomada de consciência de seu corpo que o homem do campo se dá conta da desvalorização de sua condição, agindo de modo desajeitado e com incômodo sempre que o que está em jogo é o “decoro corporal externo", essa forma de comportamento exterior que, segundo Nobert Elias (1994), passa a manifestar o homem interior, “inteiro", conforme se avança no processo civilizador.

Não por acaso, em Esboço de auto-análise (2005), publicado postumamente, Bourdieu descreve as relações de força simbólicas que atravessam os universos escolares, insistindo no papel da aparência física e da indumentária como supostos indicadores de propriedades intelectuais e morais. Nessa reconstituição dos critérios de hierarquização que estruturam o sistema de ensino francês, o autor retoma trabalhos anteriores nos quais demonstrou que as classificações escolares tendem a apontar como excelentes as qualidades dos que são socialmente dominantes, como quando fazem, por exemplo, da hexis corporal dos alunos - "suporte principal de um julgamento de classe que se ignora como tal” (Bourdieu; Saint-Martin, 1998, p. 199) - uma categoria central do juízo professoral.

Ocorre que, nestas "Observações preliminares”, o autor não deixa de insistir que toda essa linguagem do corpo "físico", da identidade "natural”, do "caráter” é, na verdade, uma linguagem da identidade social que é naturalizada e, portanto, legitimada. Mesmo no que aparentemente tem de mais natural, o corpo é produto das relações de força que atravessam a sociedade, entre outros motivos porque a desigual distribuição das propriedades corporais valorizadas ou estigmatizadas depende das mediações operadas, por exemplo, pelas condições de trabalho ou pelos hábitos de consumo. Desse modo, as diferenças de pura conformação física são redobradas por diferenças na maneira de portar o corpo, em que se exprime toda uma relação com o mundo social. Se os tratamentos (cosméticos, cirúrgicos) e as "escolhas" indumentárias dependem dos meios econômicos e culturais disponí- 
veis, pode-se dizer que a relação com o próprio corpo constitui uma forma de experimentar a posição no espaço social, tal como o sistema de signos corporais distintivos é homólogo ao sistema de posições sociais.

Designando não apenas a posição social atual, mas também a trajetória (ascendente, declinante ou estável) de seu portador, o corpo é suporte das disposições duráveis e transponíveis que constituem o habitus e podem, portanto, por um efeito de histerese, se perpetuar para além de suas condições sociais de produção. Assim é que parte deste texto agora nas mãos do leitor brasileiro será retomada em $A$ distinção, em que, precisamente, o autor se refere aos dilemas próprios àqueles que alcançam uma posição média na estrutura social; ou seja, em que discute as zonas do espaço social em que mais se recrutam os trânsfugas de classe marcados por um habitus clivado. Se, como ele afirma nestas "Observações preliminares sobre a percepção social do corpo", a experiência do desconforto e do incômodo e, de outro lado, a da facilidade e a da naturalidade são desigualmente prováveis aos membros das diferentes classes sociais - e supõem que todos os agentes atribuam o mesmo reconhecimento à representação dominante do corpo legítimo, sem estarem igualmente armados para realizá-la -, o mal-estar e o embaraço acometeriam especialmente os que vivenciam a experiência pequeno-burguesa do mundo social.

Prolongando, de certa forma, a célebre tese da Escola Sociológica Francesa de que a classificação das coisas segue de perto a classificação dos homens (Durkheim; Mauss, 1981), Bourdieu considera não apenas que as propriedades corporais são produtos sociais, mas que as próprias categorias de percepção e apreciação dessas propriedades dependem de sua distribuição entre as classes sociais. Assim, todas as taxonomias aplicadas ao corpo percebido (gordo/magro, forte/fraco, grande/pequeno) tendem a opor hierarquicamente as propriedades mais frequentes nos dominantes àquelas mais correntes nos dominados. Como 
se estivesse a ouvir Erving Goffman, que avaliou ser preciso distinguir os "símbolos de status" dos "símbolos coletivos", pois, do contrário, estes acabam servindo para negar as diferenças entre as diversas categorias sociais (Goffman, 1951), Bourdieu diferencia-se, neste ponto, da Escola Sociológica Francesa, que trata das atitudes corporais exigidas por "uma sociedade em geral”, ao demandar que se faça uma dupla contextualização, isto é, que se associem as "técnicas do corpo" (Mauss, 1983) a um contexto histórico específico, mas, também, aos usos diferenciais determinados, no interior de uma mesma sociedade, pela trajetória social de seus integrantes.

E se, como ele diz neste artigo agora traduzido em português, o pequeno-burguês não é o único a experimentar o embaraço e o mal-estar em relação ao seu corpo, as outras vítimas preferenciais dessa atitude de permanente apreciação do próprio corpo com os olhos dos dominantes são, com efeito, as mulheres. Como o leitor familiarizado com a obra de Bourdieu notará, o tópico "O ser feminino como ser percebido", de A dominação masculina, retoma toda a análise feita sobre o pequeno-burguês como participante dominado da luta simbólica, que não porta senão um “corpo para o outro", inteiramente submetido ao veredito alheio. Mas, tanto em A distinção como em $A$ dominação masculina e Le bal des célibataires, o autor reitera o que já postulara neste artigo de 1977, isto é, que esse impiedoso olhar social que induz a um sentimento de deficiência corporal é um poder social que sempre deve boa parte de sua eficácia ao fato de encontrar, junto daqueles aos quais se aplica, o reconhecimento (a um só tempo extorquido e aceito) desses princípios classificatórios que thes são desabonadores.

Finalmente, e malgrado a tese central do artigo de que o corpo é, antes de tudo, um produto social - e a hexis corporal, uma dimensão fundamental da personalidade social -, o autor lança, ainda, outra proposição que será retomada em $A$ dominação masculina e em $A$ distinção, qual seja, a de que a distribuição 
das propriedades corporais é parcialmente independente da distribuição das propriedades que conformam a posição na hierarquia social. Nesse modo de ver, o corpo teria todas as chances de receber um valor estritamente proporcional à posição de seu portador no espaço social, se a autonomia da lógica da hereditariedade biológica em relação à lógica da hereditariedade social não privasse, às vezes, os "grandes" dos atributos corporais mais estimados, e se não atribuísse, inversamente, aos desmunidos, as propriedades corporais mais raras, como a beleza, sempre considerada "fatal", posto que passível de subverter a ordem social estabelecida. 


\section{Referências bibliográficas}

BOURDIEU, Pierre. A distinção: crítica social do julgamento. São Paulo: Edusp; Porto Alegre: Zouk, 2008 [1979].

BOURDIEU, Pierre. A dominação masculina. Rio de Janeiro: Bertrand Brasil, 2003 [1998].

BOURDIEU, Pierre. Esboço de auto-análise. São Paulo: Companhia das Letras, 2005 [2002].

BOURDIEU, Pierre. Le bal des célibataires: crise de la société paysanne en Béarn. Paris: Seuil, 2002.

BOURDIEU, Pierre; SAINT-MARTIN, Monique. As categorias do juízo professoral. In: NOGUEIRA, Maria Alice; CATANI, Afrânio. Escritos de educação. Petrópolis: Vozes, 1998 [1975]. p. 185-216.

DURKHEIM, Émile; MAUSS, Marcel. Algumas formas primitivas de classificação. In: RODRIGUES, José Albertino (Org.). Durkheim: Sociologia. São Paulo: Ática, 1981 [1903]. p. 183-203.

ELIAS, Norbert. O processo civilizador: uma história dos costumes. Rio de Janeiro: Jorge Zahar, 1994 [1939].

GOFFMAN, Erving. Symbols of class status. The British Journal of Sociology, Londres, v. 2, n. 4, p. 294-295, 1951.

MAUSS, Marcel. Les techniques du corps. In: MAUSS, Marcel. Sociologie et anthropologie, Paris: PUF, 1983 [1936]. p. 363-386.

\section{Material de imprensa}

YARAK, Aretha; ROSA, Guilherme. Cirurgias plásticas: começou a temporada de busca pela perfeição. Revista Veja, acervo digital de 14 de maio 2012. Disponível em: http://veja.abril.com.br/ noticia/saude/comecou-a-temporada-de-cirurgias-plasticas. Acesso em: 31 jul. 2012 